\title{
Polystyrene monolithic column functionalized with copper-iminodiacetate complex as a stationary phase for open tubular capillary electrochromatography
}

\author{
Shiu-Chun Chuang, Chin-Yuan Chang, Chuen-Ying Liu* \\ Department of Chemistry, National Taiwan University, 1, Sec. 4, Roosevelt Road, Taipei 10617, Taiwan
}

Available online 15 June 2004

\begin{abstract}
Polystyrene-divinylbenzene copolymer functionalized with copper-iminodiacetate complex was prepared in situ for the capillary electrochromatographic separation of amino acids and oligopeptides. The steps included silanization of the fused-silica capillary column, functionalization, polymerization, hydrolysis and complexation. For having a homogeneous polymerization system in the selected porogen, the functional monomer was obtained from the reaction of 4-vinylbenzyl chloride and diethyl iminodiacetate. Scanning electron microscopy showed that the polymeric monolith column was an open tubular column with a thickness of $0.3 \mu$ m. Various modes of hydrolysis were investigated via the electroosmatic flow measurement to find the optimization condition prior to introducing the copper ion. The influence of $\mathrm{pH}$, composition and concentration of mobile phase as well as the organic modifier were investigated. Judging from our results, the recognition performance of the prepared stationary phase might be integrated from the mechanisms of ligand exchange, electrophoretic mobility, hydrophobic interaction, and hydrogen bonding.
\end{abstract}

(C) 2004 Elsevier B.V. All rights reserved.

Keywords: Monolithic columns; Stationary phases, electrochromatography; Ligand-exchange electrochromatography; Electrochromatography; Polystyrene; Amino acids; Oligopeptides; Peptides

\section{Introduction}

Capillary electrochromatography (CEC), a separation mode integrating both features of high-performance liquid chromatography (HPLC) and capillary electrophoresis (CE) has been received great interest during the last decades. In CEC the column plays a key role, because it serves not only as the separation bed but also as the pumping device of the mobile phase. Therefore further development of CEC needs a significant advancement in column technology [1]. In recent years, the development of both silica- and polymer-based monolithic columns has become a fascinating research field in the chromatographic sciences. The reason could be that monolithic columns could eliminate the tasks of particle synthesis, the difficulty of packing columns and the need to make end frits to retain the stationary phase.

\footnotetext{
* Corresponding author. Tel.: +886 $223630231 \times 2338$; fax: +886223638543 .

E-mail address: cyliu@ntu.edu.tw (C.-Y. Liu).
}

The present work concerns only polymeric monoliths. Fréchet and co-workers [2-5] developed a novel method for the preparation of "molded" monolithic continuous rods of rigid, macroporous polymer column. This new type of chromatographic medium was prepared by an "in situ" polymerization within the confines of a chromatographic column or a capillary column, which affords the final product-desired geometry and requires no tedious packing operation. Some other related reports on acrylamide-based [6-10], methacrylate ester-based [11] and polystyrene-based monoliths $[12,13]$ as the stationary phases of CEC for the separation of amino acids, peptides and proteins are shown as the indicated literatures.

The ligand exchange mode has been widely used in separation science, some selected topics include liquid chromatography [14-16], gas chromatography with metallomesogens as stationary phases [17-20], CE [21-23], CEC [1,10,24-26] and micellar electrokinetic chromatography $[27,28]$. Recently, Chen et al. [1,25] used L-phenylalaninamide-modified monolithic silica column and L-amino acid amides as chiral selectors for lig- 
and exchange CEC enantioseparation of dansyl amino acids.

In the last two decades, a series of chelating resins have been synthesized in our laboratory. The concept of chelating resin and polymeric monolith preparation as the stationary phases of CEC will be a fascinating research field in analytical chemistry. The iminodiacetate group is a polydentate chelate group which shows high affinity towards metal ions. Although Luo et al. [29] reported the preparation of metal-immobilized iminodiacetic acid-bound molded monolithic rods of macroporous poly(glycidyl methacrylate-co-ethylene dimethacrylate) column, it was for the HPLC separation of proteins. In the present work, a monolithic polystyrene-divinylbenzene copolymer functionalized with iminodiacetate copper complex has been prepared and evaluated for the separation of chelate-forming analytes, such as underivatized amino acids and oligopeptides which are important in clinical medicine.

\section{Experimental}

\subsection{Apparatus}

All experiments were carried out in a laboratory-built unit. It consists of a $\pm 30 \mathrm{kV}$ high voltage power supply (Gamma High Voltage Research Inc., Ormond Beach, FL, USA) and a UV-Vis detector (Spectra System UV3000, Thermo Separation Products, CA, USA). Electrochromatograms were recorded and processed with a TSP ChromQuest (Thermo Separation Products, CA, USA) and PC SISC-Lab (32) data acquisition system (Scientific Information Service, Taiwan). Fused silica capillaries (Polymicro Technologies, Phoenix, AZ, USA) were of $75 \mu \mathrm{m}$ i.d. and the total length of the capillary was $75 \mathrm{~cm}$, with a distance of $50 \mathrm{~cm}$ between the injection end and the detection window.

\subsection{Reagents and chemicals}

Most chemicals were analytical reagent grade from Merck (Darmstadt, Germany). Purified water $(18 \mathrm{M} \Omega \mathrm{cm})$ from a Milli-Q water purification system (Millipore, Bedford, MA, USA) was used to prepare all solutions. The amino acids including phenylalanine $\left[\mathrm{p} K_{1} 1.83, \mathrm{p} K_{2} 9.12\right.$, isoelectric point $(\mathrm{p} I) 5.48]$, tryptophan $\left(\mathrm{p} K_{1} 2.38, \mathrm{p} K_{2}\right.$ 9.39, $\left.\mathrm{p} I 5.89\right)$, and tyrosine ( $\mathrm{p} K_{1} 2.20, \mathrm{p} K_{2}$ 9.11, $\left.\mathrm{p} I 5.66\right)$, as well as the oligopeptides including angiotensin I (Asp-Arg-Val-Tyr-IleHis-Pro-Phe-His-Leu, pI 7.80), angiotensin II (Asp-ArgVal-Tyr-Ile-His-Pro-Phe, $\mathrm{pI} 7.80)$ and $\left[\mathrm{Sar}^{1}, \mathrm{Thr}^{8}\right]$-angiotensin II [Sar-Arg-Val-Tyr-Ile-His-Pro-Thr, pI 10.14; Sar:sarcosine ( $N$-methylglycine)], 2,2-diphenyl-1-picrylhydrazyl (DPPH) were obtained from Sigma (St. Louis, MO, USA). Benzyl alcohol, divinylbenzene (DVB), potassium bromide, sodium hydroxide, sodium phosphate, monobasic and sodium phosphate, dibasic (Merck), $\alpha, \alpha$-azobisisobutyronitrile (AIBN) and phosphoric acid
(Wako, Japan), acetone, acetone- $\mathrm{d}_{6}$ in 1\% (v/v) tetramethylsilane (TMS), magnesium sulfate, sodium dihydrogenphosphate, diethyl iminodiacetate (DEIDA), hydrochloric acid, 1-propanol, toluene (Acros, Geel, Belgium), 4-vinylbenzyl chloride (VBC) (Aldrich, Milwaukee, WI, USA), pyridine (Lancaster, Lancashire, UK), magnesium sulfate, 3 -trimethoxysilylpropyl methacrylate ( $\gamma$-MPS), sodium carbonate, sodium tetraborate (TCI, Tokyo, Japan) and mesityl oxide (Perak, Berlin, Germany) were purchased from the indicated sources.

Stock solutions of the amino acids $(10 \mathrm{mM})$ and oligopeptides $(2.5 \mathrm{mg} / \mathrm{mL})$ were prepared in pure water and diluted appropriately prior to use. All solvents and solutions for CEC analysis were filtered through a $0.45 \mu \mathrm{m}$ PTFE (Millipore) or cellulose acetate membrane (Whatman).

\subsection{Silanization of the capillary column}

Fused silica capillaries ( $75 \mu \mathrm{m}$ i.d.) were first flushed with $1 \mathrm{M} \mathrm{NaOH}(30 \mathrm{~min})$, then pure water $(15 \mathrm{~min}), 1 \mathrm{M} \mathrm{HCl}$ (30 $\mathrm{min})$ and pure water $(15 \mathrm{~min})$. Before silanization, the capillaries were rinsed with methanol $(5 \mathrm{~min})$ and then dried in a gas chromatography oven at $110^{\circ} \mathrm{C}$ for $1 \mathrm{~h}$ under a nitrogen flow of $2.5 \mathrm{~kg} \mathrm{~cm}^{-2}$. The capillaries were purged with nitrogen for $20 \mathrm{~min}$, then dried at $110^{\circ} \mathrm{C}$ overnight. For in situ polymerization, the capillary wall was first functionalized by filling with 3-trimethoxysilylpropyl methacrylate $(10 \%, \mathrm{v} / \mathrm{v})$ and 1,1-diphenyl-2-picrylhydrazyl (DPPH, $0.01 \%, w / v)$ in toluene, then plugged with GC septa and reacted at $120^{\circ} \mathrm{C}$ for $24 \mathrm{~h}$. The silylated capillary was rinsed with toluene to remove unreacted material.

\subsection{In situ polymerization and functionalization}

4-Vinylbenzyl chloride $(0.1 \mathrm{~mL})$, diethyl iminodiacetate $(0.3 \mathrm{~mL})$ and pyridine $(0.1 \mathrm{~mL})$ were added to the sample vial $(5 \mathrm{~mL})$ and reacted under $60^{\circ} \mathrm{C}$. Then divinylbenzene $(0.1 \mathrm{~mL})$, toluene $(0.7 \mathrm{~mL}), n$-propanol $(0.7 \mathrm{~mL})$ and $\alpha, \alpha$-azobisbutyronitrile $(2 \mathrm{mg})$ were added to the reaction mixture. After the mixture was completely dissolved, it was introduced into the silylated capillary column. The filling step was allowed to continue for $10 \mathrm{~min}$. The capillaries were then again plugged with GC septa and the polymerization was initiated thermally by placing the capillary under GC oven at $70^{\circ} \mathrm{C}$ for $24 \mathrm{~h}$. The resulting column was washed successively with methanol and water for $30 \mathrm{~min}$, and then dried under nitrogen flow.

\subsection{Hydrolysis}

Both dynamic and static modes were carried out for the hydrolysis of the functionalized diethyl iminodiacetate. For dynamic hydrolysis, different concentration of $\mathrm{NaOH}$ solutions $(1-10 \mathrm{mM})$ and the flushing time (30-60 min) were tested. Between runs, the column was flushed with pure water for $30 \mathrm{~min}$. For static hydrolysis, $\mathrm{NaOH}$ aqueous solution; 
a mixture of $\mathrm{NaOH}$ (aq) and ethanol as well as $\mathrm{NaOH}$ (s) in ethanol were introduced into the functionalized column. The column was plugged with septa and reacted under ultrasonication. Different reagent concentration and different reaction period have been tested for the hydrolysis. Subsequently, the column was washed with pure water for at least $30 \mathrm{~min}$.

\subsection{Complexation}

Thereafter, the stationary phase was loaded with copper by perfusing the column with copper sulfate $(0.1 \mathrm{M})$ for 10 min under a nitrogen flow of $2.5 \mathrm{~kg} \mathrm{~cm}^{-2}$ and reacted at $50{ }^{\circ} \mathrm{C}$ for $1 \mathrm{~h}$.

\subsection{Electrophoresis conditions}

Before analysis, the monolithic columns were preconditioned with the running buffer. They were rinsed with methanol, pure water and buffer between runs at 1 or $2 \mathrm{~min}$ intervals. The samples were injected by siphoning at a height difference of $10 \mathrm{~cm}$ for $10 \mathrm{~s}$. Electroosmotic flow (EOF) was measured with various neutral markers, such as benzyl alcohol, acetone and mesityl oxide. The samples were mostly detected by UV light absorption measurement at $214 \mathrm{~nm}$.

\section{Results and discussion}

\subsection{Preparation of the monoliths with iminodiacetate group}

Prior to the in situ polymerization, a heterobifunctional coupling agent, $\gamma$-MPS, was selected in order to activate the inner wall of the capillary column to provide anchoring sites for the grafting of the polymer to the silica surface [7]. The concentration of $\gamma$-MPS in toluene over the range from 10 to $50 \%(\mathrm{v} / \mathrm{v})$ were prepared for the silyzation reaction. The reaction condition was at $120^{\circ} \mathrm{C}$ for $24 \mathrm{~h}$. In order to slow down the polymerization of the reagent via the vinyl group, $\mathrm{DPPH}, 0.01 \%(\mathrm{w} / \mathrm{v})$ was added to the reaction mixture as Gusev et al. [7]. However, the resulting columns were occluded when the concentration of $\gamma$-MPS were greater than $25 \%$. For having both enough affinity to graft the monolith polymer and little EOF in the column, $10 \%$ was selected for the silanization step.

To have the mutual solubility of all reactants in the polymerization step, the functional monomer was obtained via the reaction of VBC and DEIDA, but not iminodiacetic acid (IDA). The porogen used was toluene- $n$-propanol $(1: 1, \mathrm{v} / \mathrm{v})$. One disadvantage was hydrolysis is needed before introducing the metal ion. For a high yield of the functional monomer, excess molar ratio of DEIDA to VBC was used. Meanwhile pyridine was added to improve the reaction. The extent of the reaction was assessed by the ${ }^{1} \mathrm{H}$ NMR technique. It is a simple method; no need to separate the product from the reactant. Table 1 shows the comparison of chemical shift before and after the reaction. It reveals that $\delta$ for VBC at $4.68 \mathrm{ppm}(\mathrm{H}, \mathrm{s})$ is not as sensitive as that of DEIDA at $3.39 \mathrm{ppm}(\mathrm{H}, \mathrm{s})$ when the reaction was undergoing. The integral ratio of chemical shift for $\left(a^{\prime}\right)$ to $(a)+\left(a^{\prime}\right)$ would increase when the reaction was proceeded; eventually, the ratio was approaching to 1 , while that for $\left(a^{\prime}\right)$ to $\left(b^{\prime}\right)$ was $1: 2$ and remain unchanged throughout the reaction.

In the polymerization reaction, the ratio of VBC:DVB: IDEA:pyridine:porogen is 5\%:5\%:15\%:5\%:70\%, with the amount of AIBN being $0.1 \%(\mathrm{w} / \mathrm{v})$.

\subsection{Morphology of the monolithic column}

SEM photographs indicated the morphology of the inner surface of the bare fused silica column (Fig. 1A), the inner surface of the polymerized layer (Fig. 1B) and the interface between polymerized layer and the capillary inner wall (Fig. 1C). The results gave the information that the thickness of the polymerized layer on the inner surface of the capillary column was only $0.3 \mu \mathrm{m}$ and not a whole column full of the polymeric monolith. Brüggemann et al. [30] claimed that the thickness of the polymerized layer was proportional to the amount of the cross-linking agent. In this work, the amount was only $5 \%$. Increasing the amount of cross-linking agent would increase the amount of the polymer molded into the column.

\subsection{EOF measurement for the optimization of the ester hydrolysis}

In this work, ester hydrolysis should be carried out prior to the metal complexation. It can be carried out by acid-catalyzed or base-promoted way. However, acid-catalyzed ester hydrolysis is reversible, while the latter is irreversible. For getting a stable column, base promoted hydrolysis was adopted. But harsh conditions would damage the siloxane bond on the inner wall of the capillary surface. Therefore, EOF measurement was employed to assess the optimization condition.

\subsubsection{Monolith with diethyl iminodiacetate functionalities}

At this stage, the functional group of the monolith polymer is neutral. But a low EOF would be expected due to the presence of some unmodified silanol group. For selecting an ideal neutral marker to determine the quantity of the EOF, both acetone and benzyl alcohol had been used. Unfortunately, no peak was found at phosphate buffer $(\mathrm{pH} 6.0$, $20 \mathrm{mM}$ ) even the elution time was longer than $400 \mathrm{~min}$. However, a greater mobility was demonstrated when more runs were carried out (Fig. 2), and eventually a stable EOF was obtained. At first stage, the retention time of benzyl alcohol and that of acetone was not the same value. The difference decreased gradually as the extent of hydrolysis increased. We can say that the retention behavior is mainly based on chromatography, but as the extent of hydrolysis increased, 
Table 1

Comparison of ${ }^{1} \mathrm{H}$ NMR chemical shift before and after reaction of 4-vinylbenzyl chloride and diethyl imnodiacetate<smiles>C=Cc1ccc(CCl)cc1</smiles>

$V B C$<smiles>CCOC(=O)CNCC(=O)OCC</smiles>

(b)
DEIDA

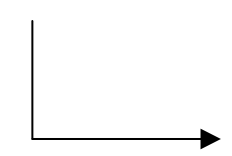

$\sim 60^{\circ} \mathrm{C}, 30 \mathrm{~min}$. or $60 \mathrm{~min}$<smiles>C=Cc1ccc(CN(CC(=O)OCC)CC(=O)OCC)cc1</smiles>

$+\mathrm{HCl}$

Reactants

Chemical shift, $\delta$ (ppm)

Before reaction

(a)

(b)

4.68

3.39

After reaction

(a)

(b)

$\left(\mathrm{a}^{\prime}\right)$

$\left(b^{\prime}\right)$
4.70

3.65

3.88

3.52 electrophoretic behavior commenced to play the predominant role of the migration.

\subsubsection{Ester hydrolysis with dynamic method}

Hereafter dynamic method with $\mathrm{NaOH}$ aqueous solution was tested to see the performance. The concentrations of $\mathrm{NaOH}$ and the flushing time were as follows: $1 \mathrm{mM} \mathrm{NaOH}$, 30 min (condition A), $1 \mathrm{mM} \mathrm{NaOH}, 60$ min (condition $\mathrm{B}$ ); and $10 \mathrm{mM} \mathrm{NaOH}, 60 \mathrm{~min}$ (condition $\mathrm{C}$ ). The EOF of the resulting column hydrolyzed with different conditions was presented as Fig. 3. It was found that no significant difference was for each process, and the column with the lowest retention time was that hydrolyzed with the mildest condition (A). This is rather surprising, and we wonder whether there is unfavorable interaction between hydroxyphenyl in the marker and the hydrolyzed iminodiacetate functional group. For the consideration, mesityl oxide was chosen as the marker for the further study.

\subsubsection{Ester hydrolysis with static method}

3.3.3.1. Sodium hydroxide aqueous solution. This was investigated by varying the concentration of $\mathrm{NaOH}$ aqueous solution $(10,50$ and $100 \mathrm{mM})$ with ultrasonication at $58^{\circ} \mathrm{C}$

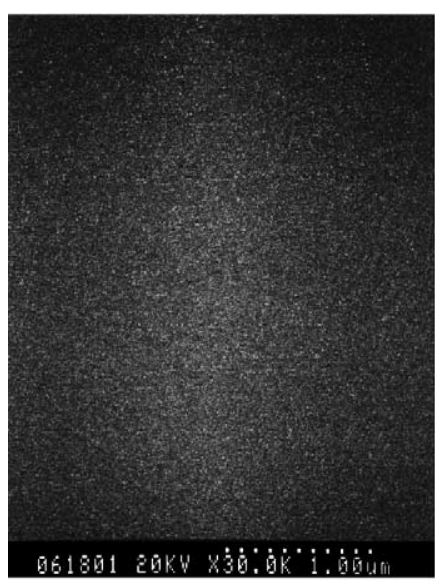

(A)

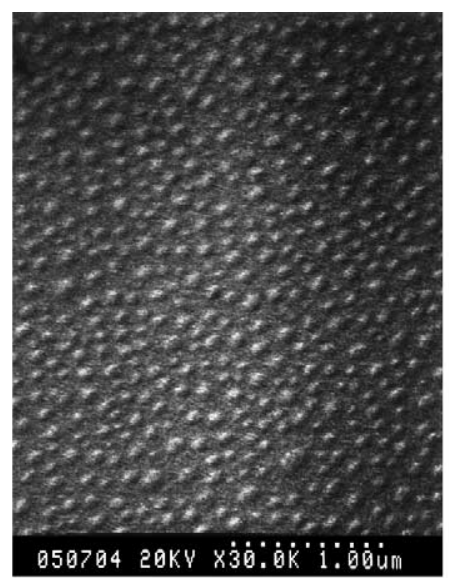

(B)

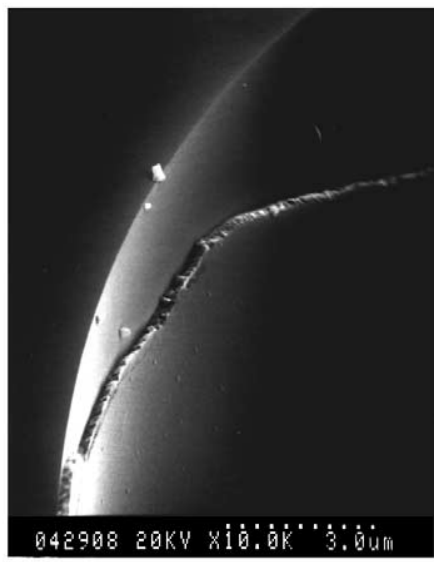

(C)

Fig. 1. Scanning electron micrographs of (A) the inner surface of bare column, (B) the inner surface of polymerized layer, (C) the interface between polymerized layer and capillary inner wall. 


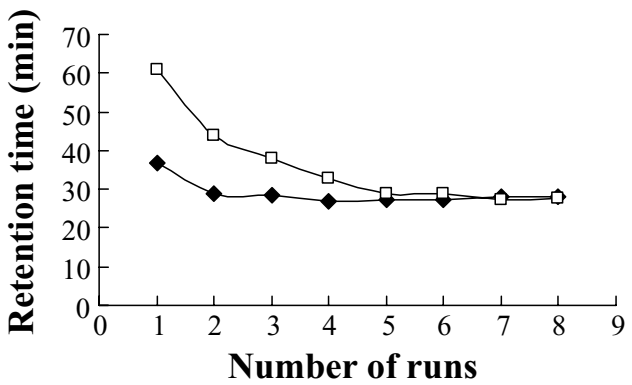

Fig. 2. The retention time of the marker in the monolith with diethyliminodiacetate (DEIDA) functionalities. Column: $75 \mathrm{~cm}(50 \mathrm{~cm}$ to detector) $\times 75 \mu \mathrm{m}$ i.d.; mobile phase: phosphate buffer $(20 \mathrm{mM}, \mathrm{pH} 6.0)$; injection mode: hydrostatic injection $(10 \mathrm{~cm}, 5 \mathrm{~s})$; markers: benzyl alcohol and acetone; applied voltage: $15 \mathrm{kV}$; detection wavelength: $220 \mathrm{~nm}$ (acetone), $214 \mathrm{~nm}$ (benzyl alcohol). ( ) Benzyl alcohol; $(\square)$ acetone.

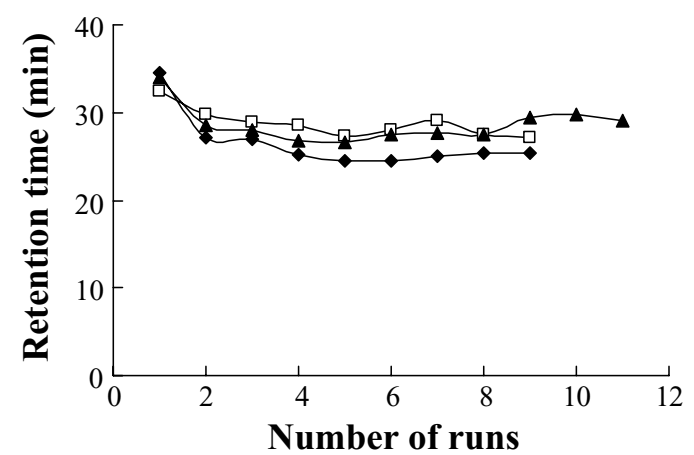

Fig. 3. The retention time of marker in the DEIDA monolith column hydrolyzed with $\mathrm{NaOH}$ aqueous solution by dynamic method. Conditions as Fig. 2 except marker: benzyl alcohol. Hydrolysis conditions: A: $\mathrm{NaOH}$ (1 mM, $30 \mathrm{~min})$; B: $\mathrm{NaOH}(1 \mathrm{mM}, 60 \mathrm{~min})$; $\mathrm{C}: \mathrm{NaOH}(10 \mathrm{mM}, 60 \mathrm{~min})$. $(\diamond)$ Condition A; $(\square)$ condition B; $(\boldsymbol{\Delta})$ condition $\mathrm{C}$.

for $2 \mathrm{~h}$. The results indicated that the capillary column was collapsed after hydrolysis with $100 \mathrm{mM} \mathrm{NaOH}$. The EOF was even similar to that of the bare fused silica column (Fig. 4). Attached polymer layer felled off could also be observed for the column hydrolyzed with $50 \mathrm{mM} \mathrm{NaOH}$.

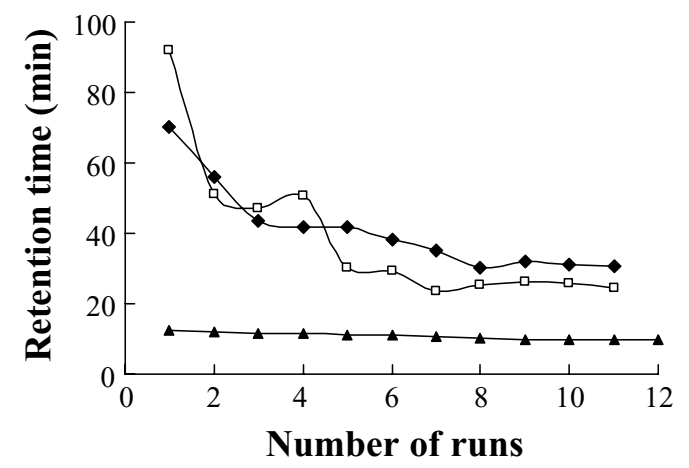

Fig. 4. The retention time of marker in the DEIDA monolith column hydrolyzed by static method. Conditions as Fig. 2 except marker: mesityl oxide. Hydrolysis with $\mathrm{NaOH}$ aqueous solutions. ( $) 10 \mathrm{mM} \mathrm{NaOH}$; $(\square)$ $50 \mathrm{mM} \mathrm{NaOH} ;(\boldsymbol{\Delta}) 100 \mathrm{mM} \mathrm{NaOH}$.

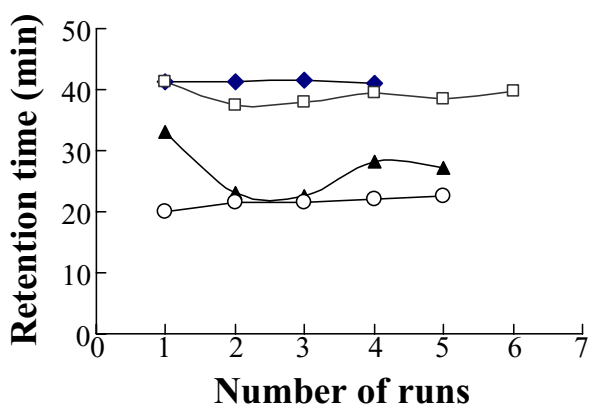

Fig. 5. The retention time of marker in the DEIDA monolith column hydrolyzed by static method. Conditions as Fig. 4 except hydrolysis conditions with the mixture of $\mathrm{NaOH}-\mathrm{EtOH}(1: 1, \mathrm{v} / \mathrm{v})$ solution. (Two different columns were employed for each hydrolyzed solvent.) $(\diamond) \mathrm{NaOH}$ (10 mM)-EtOH (column 1); ( $\square) \mathrm{NaOH}(10 \mathrm{mM}$ )-EtOH (column 2); (ム) $\mathrm{NaOH}(100 \mathrm{mM})-\mathrm{EtOH}($ column 1$) ;(\bigcirc) \mathrm{NaOH}(100 \mathrm{mM})-\mathrm{EtOH}$ (column 2).

3.3.3.2. Mixture of sodium hydroxide aqueous solution and ethyl alcohol. Since ester moiety of the monolith polymer is more hydrophobic than the siloxane bond, this suggests that a mixture of $\mathrm{NaOH}(\mathrm{aq})-\mathrm{EtOH}(1: 1, \mathrm{v} / \mathrm{v})$ as the hydrolyzed solvent would be more advantageous. Here ultrasonication at $42^{\circ} \mathrm{C}$ with different reaction time $(2-3 \mathrm{~h})$ was applied in each case (Fig. 5). The results indicated that hydrolysis with $\mathrm{NaOH}(10 \mathrm{mM})-\mathrm{EtOH}$ was better than that with $\mathrm{NaOH}(100 \mathrm{mM})-\mathrm{EtOH}$, and $2 \mathrm{~h}$ was enough for the process.

3.3.3.3. Sodium hydroxide ( $s$ ) in ethyl alcohol. Hydrolysis was further manipulated by dissolving the solid $\mathrm{NaOH}$ in EtOH. $\mathrm{NaOH}$ ethanol solution $(10 \mathrm{mM})$ was filled into the DEIDA column and then reacted at $58^{\circ} \mathrm{C}$ for $2 \mathrm{~h}$ with ultrasonication. It did provide more highly reproducible results. The retention time (min) was $20.21 \pm 3.03 \%(n=4)$ for the EOF measurement after each hydrolyzed column freshly prepared. For this reason, a $\mathrm{NaOH}$ (s)-EtOH $(10 \mathrm{mM})$ was chosen as the optimum condition for the ester hydrolysis.

\subsection{Complexation}

For introducing metal ion in the monolith column, copper sulfate with $0.1 \mathrm{M}$ at $\mathrm{pH} 4-5$ was carried out. The logarithm of the stability constant for copper-iminodiacetate complex is $10.56 \pm 0.05\left(25^{\circ} \mathrm{C}, \mu=0.1\right)$ [31]. So the experimental condition is favorable for introducing copper ion into the monolith polymer. To which the polydentate ligand forms a stable two five-membered chelating ring.

\subsection{Evaluation the separation efficiency of the monolith column}

\subsubsection{Separation of amino acids}

3.5.1.1. $p H$ of the mobile phase. Without copper ion, the iminodiacetate-bound stationary phase would be a cation 
Table 2

Retention behavior of underivatized amino acids on the $\mathrm{Cu}$-iminodiacetate monolithic column with different background electrolytes ${ }^{\mathrm{a}}$

\begin{tabular}{|c|c|c|c|c|c|c|c|c|c|}
\hline \multirow[t]{2}{*}{ Analyte } & \multicolumn{3}{|c|}{ Retention time (min) } & \multicolumn{3}{|c|}{$W_{1 / 2}(\min )$} & \multicolumn{3}{|c|}{ Theoretical plate number $\left(\mathrm{m}^{-1}\right)$} \\
\hline & $\mathrm{pH} 7.0$ & $\mathrm{pH} 8.0$ & $\mathrm{pH} 9.0$ & $\mathrm{pH} 7.0$ & $\mathrm{pH} 8.0$ & $\mathrm{pH} 9.0$ & $\mathrm{pH} 7.0$ & $\mathrm{pH} 8.0$ & $\mathrm{pH} 9.0$ \\
\hline Tryptophan ${ }^{b}$ & 13.95 & $13.50(9.38)^{\mathrm{d}}$ & 15.93 & 0.36 & 0.82 & 1.03 & 8300 & 1500 & 1300 \\
\hline Tryptophan ${ }^{\mathrm{c}}$ & 14.48 & 13.94 & & 0.42 & 0.49 & & 6700 & 4400 & \\
\hline Tyrosine $^{b}$ & 14.67 & $16.17(9.22)$ & 16.70 & 0.18 & 0.33 & 0.71 & 38800 & 13300 & 3100 \\
\hline Tyrosine $^{c}$ & 14.49 & 14.56 & & 0.38 & 0.50 & & 8100 & 4700 & \\
\hline Phenylalanine ${ }^{b}$ & 13.90 & $15.05(9.55)$ & 15.67 & 0.13 & 0.10 & 0.59 & 59500 & 133800 & 3900 \\
\hline Phenylalanine ${ }^{c}$ & 13.15 & 13.67 & & 0.24 & 0.33 & & 17200 & 9600 & \\
\hline
\end{tabular}

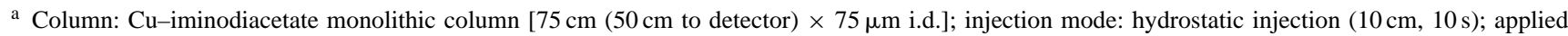
voltage: $15 \mathrm{kV}$; detection wavelength: $214 \mathrm{~nm}$.

b Phosphate buffer $(20 \mathrm{mM})$.

c Carbonate buffer $(20 \mathrm{mM})$.

${ }^{\mathrm{d}}$ Conditions as in footnotes a and b except column is bare fused-silica column.

exchanger. To ensure greater stability of the copper complex, $\mathrm{pH}$ was maintained over the range from 6 to 8. Under these conditions, all the analyte existed in the anionic form. Both tyrosine and phenylalanine were coeluted with the neutral marker at $\mathrm{pH}$ 6.0. After increase of the $\mathrm{pH}$ to 7.0, the retention time differences between marker and phenylalanine (Phe), tryptophan (Trp) and tyrosine (Tyr) were 0.39, 0.57, and $0.67 \mathrm{~min}$, respectively. The elution order was Phe > Trp $>$ Tyr. On further increase of the $\mathrm{pH}$ to 8.0, the differences between them were increased to $2.42,1.69$ and $2.85 \mathrm{~min}$, respectively. The elution order was changed to $\operatorname{Trp}>$ Phe > Tyr.

3.5.1.2. Composition of the mobile phase. An important factor in any chromatographic separation is the mobile phase composition. Since with the use of phosphate buffer $(20 \mathrm{mM}$, $\mathrm{pH}$ 6.0-8.0) and applied voltage of $15 \mathrm{kV}$, the three peaks were not fully separated and peak tailing was demonstrated, the following species: $\mathrm{H}_{2} \mathrm{PO}_{4}{ }^{-}, \mathrm{HPO}_{4}{ }^{2-}, \mathrm{PO}_{4}{ }^{3-}, \mathrm{HCO}_{3}{ }^{-}$ and $\mathrm{CO}_{3}{ }^{2-}$ with conductivities ( $\mathrm{S} \mathrm{cm}^{2} /$ equiv.) being 33,57 , $69,44.5$ and 72 , respectively were considered. For the subsequent work, bicarbonate buffer with a lower conductivity was tested to see the performance. Unfortunately, peak tailing was not improved and even more serious in higher $\mathrm{pH}$ medium. At $\mathrm{pH}$ 9.0, copper hydroxide and higher conductivity buffer species, $\mathrm{CO}_{3}{ }^{2-}$ or $\mathrm{PO}_{4}{ }^{3-}$ would form. These resulted in a poorer performance of the column (Table 2). By considering the resolution, peak width and the number of theoretical plate, phosphate buffer with $\mathrm{pH} 8.0$ was selected for the further work.

3.5.1.3. Concentration of the mobile phase. At phosphate buffer of $\mathrm{pH} 8.0$, the effect of the buffer concentration on the retention times was studied over the range from 10 to $50 \mathrm{mM}$. Two peaks could be found at $40 \mathrm{mM}$ buffer. On increasing the concentration of phosphate buffer to $50 \mathrm{mM}$, three non-resolved peaks were obtained.

3.5.1.4. Additive of the mobile phase. At phosphate buffer $(\mathrm{pH} 8.0,50 \mathrm{mM})$ and applied voltage of $15 \mathrm{kV}$, further op- timization of the resolution was achieved by the addition of acetonitrile. Resolution was improved by changing the acetonitrile content from 10 into $20 \%$. The electrochromatograms were as indicated in Fig. 6. The elution order was Trp > Tyr > Phe.

\subsubsection{Separation of oligopeptides}

In a preliminary test, varying the $\mathrm{pH}$ value from 7.0 to 8.0 , the phosphate buffer concentration in the range of $20-50 \mathrm{mM}$, the acetonitrile content of $20-50 \%(\mathrm{v} / \mathrm{v})$, no peak was found (at $214 \mathrm{~nm}$ ) within a reasonable time

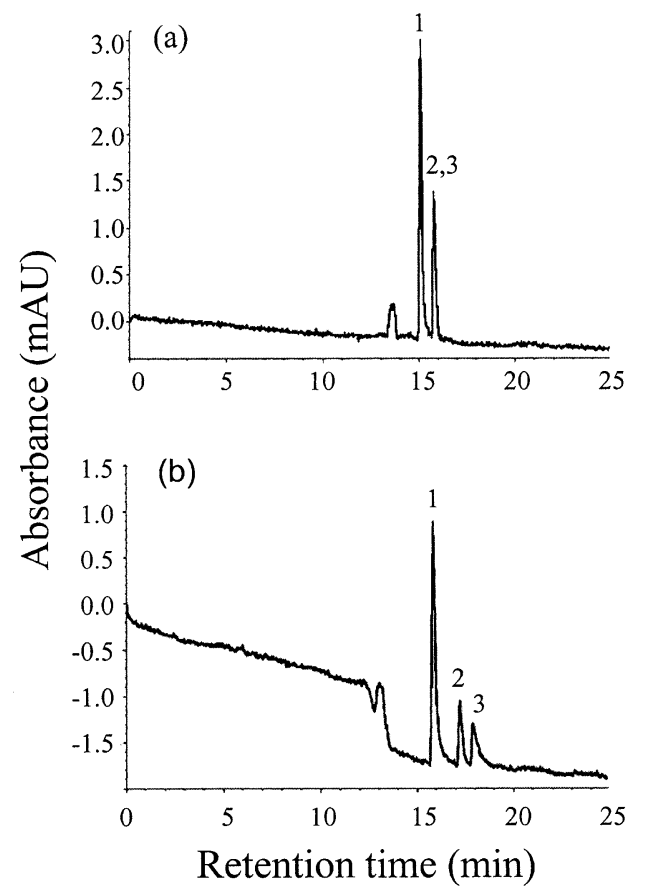

Fig. 6. Electrochromatograms of amino acid mixture with various amount of acetonitrile in phosphate buffer. Column: $\mathrm{Cu}$-iminodiacetate monolith column $[75 \mathrm{~cm}(50 \mathrm{~cm}$ to detector $) \times 75 \mu \mathrm{m}$ i.d.]; injection mode: hydrostatic injection $(10 \mathrm{~cm}, 10 \mathrm{~s})$; applied voltage: $15 \mathrm{kV}$; detection wavelength: $214 \mathrm{~nm}$; mobile phase: phosphate buffer $(50 \mathrm{mM}, \mathrm{pH} 8.0)$ with the addition of acetonitrile (?\%, v/v) (a) 10\% (b) 20\%; peak identification: 1 $=$ tryptophan; $2=$ tyrosine; $3=$ phenylalanine. 


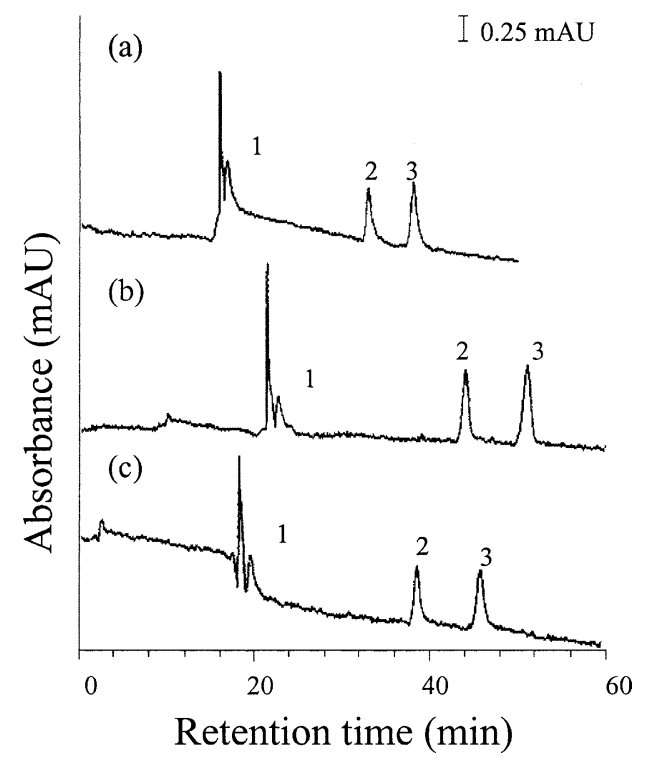

Fig. 7. Electrochromatograms of peptide mixture with various amount of acetonitrile in borate buffer. Conditions as Fig. 6, except sample: $0.42 \mathrm{mg} / \mathrm{ml}$ of each dissolved in pure water; applied voltage: $20 \mathrm{kV}$; detection wavelength: $200 \mathrm{~nm}$; mobile phase: borate buffer $(20 \mathrm{mM}, \mathrm{pH}$ 8.5 ) with the addition of acetonitrile (?\%, v/v) (a) $10 \%$ (b) $20 \%$ (c) $30 \%$; peak identification: $1=\left[\mathrm{Sar}^{1}, \mathrm{Thr}^{8}\right]$ angiotensin II; $2=$ angiotensin I; 3 $=$ angiotensin II.

when three analytes including angiotensin I, angiotensin II and $\left[\mathrm{Sar}^{1}, \mathrm{Thr}^{8}\right]$-angiotensin II were injected. But mesityl oxide could be detected in a symmetric peak. The results indicated a serious adsorption of these analytes might be on the prepared column. With borate buffer ( $\mathrm{pH} 8.5$, $20 \mathrm{mM}$ ) and detection at $200 \mathrm{~nm}$, two peaks could be found. The addition of acetonitrile at $10 \%$ to the borate buffer led to three well-resolved peaks. The elution order was $\left[\mathrm{Sar}^{1}, \mathrm{Thr}^{8}\right]$-angiotensin II $>$ angiotensin I > angiotensin II.

On increasing the acetonitrile content over the range from 10 to $20 \%$, a longer retention time was indicated. A small EOF might be the reason. Furthermore increase the acetonitrile content to $30 \%$, it would have a greater hydrophobic interaction with the polymer backbone and less favorable condition for the complexation. All of it resulted in a lower affinity for the analyte (Fig. 7).

\subsection{Retention mechanism suggested for the model compounds separation}

\subsubsection{Separation of amino acids}

In this work, sample was injected from the anodic end. Since analytes carries negative charge, the EOF which originated from the uncomplexed iminodiacetate and unmodified silanol groups was found strong enough to carry the analyte to the cathode. Based on the electrophoresis, it would be difficult to separate the compounds with similar ionic mobility. However, the elution order is $\operatorname{Trp}>\mathrm{Tyr}>\mathrm{Phe}$. For the comparison, a bare fused-silica column was employed to separate the model compounds in the similar condition. Not only much lower retention but also no significant difference for the migration time was shown (Table 2).

The side chain of phenylalanine has least polarity among the three analytes, whereas tyrosine and tryptophan have intermediate polarity. By judging from the hydrophobic interaction with the polymer matrix, the elution order should be $\operatorname{Trp} \approx \mathrm{Tyr}>$ Phe.

Here complex formation between stationary phase ligand and the analyte is a heterogeneous reaction. In the homogeneous system, the stability constant for the copper complex decrease in the order: Trp > Tyr $>$ Phe [31]. However, the affinity for the heterogeneous complexation might have somewhat difference from that of the homogeneous one. Due to tryptophan has an additional indole, tyrosine has a $p$-hydroxyphenyl group, greater steric hindrance might have in the monolith polymer. Therefore the elution order is $\operatorname{Trp}$ $>$ Tyr $>$ Phe.

\subsubsection{Separation of oligopepetides}

The $\mathrm{p} I$ value for angiotensin I is 7.80 , angiotensin II is 7.80 and $\left[\mathrm{Sar}^{1}, \mathrm{Thr}^{8}\right]$-angiotensin II is 10.14 . Under the experimental conditions ( $\mathrm{pH}$ 8.5), angiotensins I and II are in the anionic form and the other one is in the cationic form. When voltage was applied, the cationic form would migrate fast and the anionic form move more slowly.

In order to further elucidate the retention mechanism, the complexation ability toward the central metal ion was considered. Angiotensin I has complexing groups on the side chain of Asp, Arg, His, His as well as the carboxylate and the amino group on the N-terminal Asp; Angiotensin II has one less His complexing group than angiotensin I. $\left[\mathrm{Sar}^{1}, \mathrm{Thr}^{8}\right]$-Angiotensin II has only two complexing groups on the side chain of Arg and His and no N-terminal complexing group due to the $N$-methylation of the sarcosine. In summary, $\left[\mathrm{Sar}^{1}, \mathrm{Thr}^{8}\right]$-angiotensin II would be eluted earliest. Although greater complexation affinity would be expected for angiotensin I, a greater steric hindrance due to larger peptide chain might hinder the complexation reaction. Therefore it was eluted earlier than angiotensin II.

In view of the hydrophobic interaction for the peptides, longer retention time (Fig. 7) than that for amino acids (Fig. 6) indicates that a stronger interaction force with the polymer matrix.

\section{Conclusion}

In this work, a novel monolith polymer column was prepared. The steps included silanization, functionalization, polymerization, hydrolysis and metal complexation. To assess the ester hydrolysis, the quantity of EOF was measured. It was found that $\mathrm{NaOH}(\mathrm{s})-\mathrm{EtOH}(10 \mathrm{mM})$ was the most advantageous one. After complexation, the monolith polymer was used as the stationary phase of ligand-exchange CEC. Amino acids and oligopeptides with similar ionic mobility were chosen as the model compounds for evaluation 
the separation performance. Judging from our results, the retention order of the model compounds seems to depend mainly on ligand exchange, electrophoretic mobility, but hydrophobic interaction and hydrogen bonding etc would also have to be considered.

Ligand-exchange CEC is an attractive analytical technique due to its versatility. Besides electrophoretic behavior, the type of the polymer-base, the ligand attached and the central metal ion, all the changes could play different role for the CEC separation. However, a labile complex is suggested for the kinetic reason.

\section{Acknowledgements}

The authors thank the National Science Council of Taiwan for financial support.

\section{References}

[1] Z. Chen, T. Hobo, Anal. Chem. 73 (2001) 3348.

[2] F. Svec, J.M.J. Fréchet, Anal. Chem. 64 (1992) 820.

[3] E. Peters, M. Petro, F. Svec, J.M.J. Fréchet, Anal. Chem. 70 (1998) 2288.

[4] E. Peters, M. Petro, F. Svec, J.M.J. Fréchet, Anal. Chem. 70 (1998) 2296.

[5] Q.C. Wang, F. Svec, J.M.J. Fréchet, Anal. Chem. 65 (1993) 2243.

[6] A. Palm, M.V. Novotny, Anal. Chem. 69 (1997) 4499.

[7] I. Gusev, X. Huang, Cs. Horváth, J. Chromatogr. A 855 (1999) 273.

[8] C. Ericson, S. Hjertén, Anal. Chem. 71 (1999) 1621.

[9] S. Zhang, J. Zhang, Cs. Horváth, J. Chromatogr. A 914 (2001) 189.
[10] M.G. Schmid, N. Grobuschek, C. Tuscher, G. Gübitz, Á. Végvári, E. Machtejevas, A. Maruška, S. Hjertén, Electrophoresis 21 (2000) 3141.

[11] R. Shediac, S.M. Ngola, D.J. Throckmorton, D.S. Anex, T.J. Shepodd, A.K. Singh, J. Chromatogr. A 925 (2001) 251.

[12] R. Wu, H. Zou, M. Ye, Z. Lei, J. Ni, Anal. Chem. 73 (2001) 4918.

[13] D.J. Throckmorton, T.J. Shepodd, A.K. Singh, Anal. Chem. 74 (2002) 784.

[14] V.A. Davankov, S.V. Rogozhin, J. Chromatogr. 60 (1971) 280.

[15] C.Y. Liu, C.C. Hu, K.Y. Yeh, M.J. Chen, Fresenius J. Anal. Chem. 339 (1991) 877.

[16] S.D. Chyueh, C.Y. Liu, Fresenius J. Anal. Chem. 354 (1996) 278.

[17] C.C. Hu, C.Y. Liu, Anal. Chim. Acta. 332 (1996) 23.

[18] C.Y. Liu, C.C. Hu, C.L. Yang, J. Chromatogr. A 773 (1997) 199.

[19] C.Y. Liu, J.L. Chen, C.C. Shiue, K.T. Liu, J. Chromatogr. A 862 (1999) 65.

[20] C.Y. Liu, S.H. Yang, M.H. Chau, C.C. Shiue, J. Chromatogr. A 933 (2001) 117

[21] X. Lu, Y. Chen, L. Guo, Y. Yang, J. Chromatogr. A 945 (2002) 249.

[22] S. Kodama, A. Yamamoto, A. Matsunaga, K. Hayakawa, J. Chromatogr. A 932 (2001) 139.

[23] V.A. Davankov, J. Chromatogr. A 1000 (2003) 891.

[24] T.S. Chen, C.Y. Liu, Electrophoresis 22 (2001) 2606.

[25] Z. Chen, M. Niitsuma, K. Uchiyama, T. Hobo, J. Chromatogr. A 990 (2003) 75.

[26] O. Lecnik, G. Gübitz, M.G. Schmid, Electrophoresis 24 (2003) 2983.

[27] N.G. Sundin, T.M. Dowling, N. Grinberg, G. Bicker, J. Microcol. Sep. 8 (1996) 323.

[28] Z. Chen, J.M. Lin, K. Uchiyama, T. Hobo, Chromatographia 49 (1999) 436.

[29] Q. Luo, H. Zou, X. Xiao, Z. Guo, L. Kong, X. Mao, J. Chromatogr. A 926 (2001) 255.

[30] O. Brüggemann, R. Freitag, M.J. Whitcombe, E.N. Vulfson, J. Chromatogr. A 781 (1997) 43.

[31] R.M. Smith, A.E. Martell, Critical Stability Constants, vol. 6, Plenum Press, New York, 1989. 